Original Article

\title{
Extraluminal Placement of a Bronchial Blocker Compared with Carbon Dioxide Artificial Pneumothorax in Infants Undergoing Video-Assisted Thoracoscopic Surgery
}

\author{
Jing Wang, MD, ${ }^{1,2,3,4}$ Wen-Peng Xie, MM, ${ }^{1,2,3,4}$ Yu-Qing Lei, MM, ${ }^{1,2,3,4}$ Ling-Shan Yu, MD, ${ }^{1,2,3,4}$
}

Zeng-Chun Wang, MD, 1,2,3,4 Hua Cao, MD, ${ }^{1,2,3,4}$ and Qiang Chen, MD ${ }^{1,2,3,4}$

\begin{abstract}
Objective: To investigate the safety and effectiveness of extraluminal placement of a bronchial blocker compared with carbon dioxide $\left(\mathrm{CO}_{2}\right)$ artificial pneumothorax in infants undergoing video-assisted thoracoscopic surgery (VATS).

Methods: The study involved 33 infants (group A) who underwent one-lung ventilation (OLV) with extraluminal placement of a bronchial blocker and 35 other infants (group B) who underwent $\mathrm{CO}_{2}$ artificial pneumothorax. Clinical characteristics, the degree of lung collapse, and complications were compared.

Results: The degree of lung collapse in group A was significantly higher than that in group $B$ at T2 and T3. The mean arterial pressure (MAP) of group B was significantly lower than that of group $A$ at $10 \mathrm{~min}$ and $30 \mathrm{~min}$ after OLV. The partial pressure of carbon dioxide $\left(\mathrm{PaCO}_{2}\right)$ of group $\mathrm{B}$ was significantly higher than that of group $\mathrm{A}$ at $30 \mathrm{~min}$ after OLV. The incidence of hypotension in group B was higher than that in group $A$.

Conclusion: Compared with $\mathrm{CO}_{2}$ artificial pneumothorax, extraluminal placement of a bronchial blocker is associated with a better degree of lung collapse, fewer episodes of hypotension, and lower $\mathrm{PaCO}_{2}$ accumulation during OLV in infants undergoing VATS.
\end{abstract}

Keywords: one-lung ventilation, bronchial blockers, artificial pneumothorax, infants, anesthesia

\footnotetext{
${ }^{1}$ Department of Cardiac Surgery, Fujian Maternity and Child Health Hospital, Affiliated Hospital of Fujian Medical University, Fuzhou, China

${ }^{2}$ Fujian Key Laboratory of Women and Children's Critical Diseases Research, Fujian Maternity and Child Health Hospital, Fuzhou, China

${ }^{3}$ Fujian Branch of Shanghai Children's Medical Center, Fuzhou, China

${ }^{4}$ Fujian Children's Hospital, Fuzhou, China
}

Received: March 1, 2021; Accepted: May 10, 2021

Corresponding author: Qiang Chen, MD. Department of Cardiac Surgery, Fujian Maternity and Child Health Hospital, Affiliated Hospital of Fujian Medical University, Fuzhou, China Email: chenqiang2228@163.com

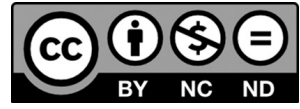

This work is licensed under a Creative Commons Attribution-NonCommercialNoDerivatives International License.

(C)2021 The Editorial Committee of Annals of Thoracic and Cardiovascular Surgery

\section{Introduction}

In recent years, video-assisted thoracoscopic surgery (VATS) has been increasingly used in pediatric thoracic surgery. In this process, lung collapse is induced to provide an adequate surgical field of vision. Carbon dioxide $\left(\mathrm{CO}_{2}\right)$ artificial pneumothorax is usually used to provide adequate operating conditions for VATS. ${ }^{1,2}$ However, this method may lead to hemodynamic changes, such as hypotension. ${ }^{3)}$ The use of a bronchial blocker can induce collapse of the lung on the operative side of the chest, and the mode of ventilation can be changed at any time during the operation. The secretions of the lung on the operation side can be aspirated at any time, and this is widely applied with good effect. ${ }^{4,5)}$ A fiberoptic bronchoscope is used to locate the bronchial blocker after bronchial blocker placement. As the airway diameter of 
Wang J, et al.

infants is relatively small, it can be difficult to operate a fiberoptic bronchoscope. Bronchial blocker placement in the endotracheal tube may increase airway pressure and reduce sufficient ventilation. Therefore, during VATS in infants, a bronchial blocker can be placed outside the endotracheal tube for one-lung ventilation (OLV) to achieve lung collapse. ${ }^{6-9)}$ In this study, the data of infants undergoing VATS in our hospital from February 2018 to December 2020 were retrospectively analyzed to compare the safety and feasibility of extraluminal bronchial blocker placement and $\mathrm{CO}_{2}$ artificial pneumothorax in those patients.

\section{Materials and Methods}

The Ethics Committee of Fujian Maternal and Child Health Hospital approved this retrospective study. The study was conducted following the Declaration of Helsinki's ethical standards and its later amendments.

From February 2018 to December 2020, data were collected for 68 children through the medical record system, including 33 children in the bronchial blocker group (group A) and 35 children in the $\mathrm{CO}_{2}$ artificial pneumothorax group (group B). Relevant general clinical data were collected (Table 1). The inclusion criteria were as follows: the infants were aged 2-12 months and underwent video-assisted thoracoscopic pulmonary lobectomy or segmentectomy in our hospital; extraluminal placement of a bronchial blocker or artificial pneumothorax with $\mathrm{CO}_{2}$ was used to induce lung collapse; the patient's diagnosis was congenital cystic adenomatoid malformation of lung sequestration; and the family members signed informed consent. The exclusion criteria were as follows: the patient had other severe medical conditions, such as pulmonary insufficiency or liver and kidney insufficiency; and the patient underwent alternative surgical procedures or was converted to conventional open-chest surgery intraoperatively. The family members of the patient were informed of the anesthetic and surgical options before the surgery, and different lung collapse options were selected according to the decision of the anesthesiologist and surgeon.

All infants fasted for 4 hours and did not consume water for 2 hours. They were sedated with $0.1 \mathrm{mg} / \mathrm{kg}$ midazolam by intravenous injection. After entering the operating room, physiologic saline was infused. Heart rate (HR), noninvasive blood pressure, electrocardiograph (ECG), and oxygen saturation $\left(\mathrm{SpO}_{2}\right)$ were monitored. Anesthesia was induced by intravenous injection of propofol at $2-3 \mathrm{mg} / \mathrm{kg}$, fentanyl at $3-5 \mu \mathrm{g} / \mathrm{kg}$, and rocuronium at $0.6 \mathrm{mg} / \mathrm{kg}$.

In group $\mathrm{A}$, the glottis was exposed under a visual laryngoscope after mask inhalation of oxygen for 2 minutes. The smallest 5F bronchial blocker (Hangzhou Tappa Medical Technology Co., Ltd.) was inserted into the trachea. An uncuffed endotracheal tube was also inserted into the trachea to place the bronchial blocker outside the endotracheal tube. The endotracheal tube was adjusted approximately $1-2 \mathrm{~cm}$ away from the carina of the trachea using a fiberoptic bronchoscope, and the bronchial blocker was guided into the pulmonary region of the operative side. Next, $1-3 \mathrm{~mL}$ of air was injected into the cuff of the bronchial blocker. The anesthesiologist auscultated both sides of the chest, and disappearance of the sound of pulmonary respiration on the operative side indicated that the bronchial blocker was in the correct position. In this study, the bronchial blocker was placed in the right main bronchus, the right middle and right lower bronchus, the left main bronchus, and the left lower bronchus, depending on the surgical scope. After the cuff was deflated, the endotracheal tube was connected to the anesthesia machine for two-lung mechanical ventilation. The following pressure control mode was adopted: fraction of inspired oxygen $\left(\mathrm{FiO}_{2}\right)$ of 0.5 , positive end-expiratory pressure (PEEP) of 3-5 mmHg, inspiratory/expiratory (I:E) ratio of 1:1.5, tidal volume (VT) of $8-10 \mathrm{~mL} / \mathrm{kg}$, respiratory frequency (R) of 30-35 times per minute, and oxygen flow rate of 2-3 L/min. Before skin incision, a fiberoptic bronchoscope was used again to determine the position of the cuff of the bronchial blocker. After entering the thoracic cavity on the operative side, the correct amount of air was injected into the cuff of the bronchial blocker, and one-lung mechanical ventilation was performed. The following pressure control mode was adopted: $\mathrm{FiO}_{2}$ of $0.8-1.0$, PEEP of $3-5 \mathrm{mmHg}$, I:E ratio of $1: 1.5$, VT of 6-8 $\mathrm{mL} / \mathrm{kg}, \mathrm{R}$ of $30-35$ times per minute, and oxygen flow rate of $2-3 \mathrm{~L} / \mathrm{min}$. No additional $\mathrm{CO}_{2}$ insufflation was needed in this group.

In group B, the endotracheal tube was inserted into the principal bronchus, and mechanical ventilation was performed after concordant auscultatory breath sounds were noted in both lungs. After the infant was in the lateral position, $\mathrm{CO}_{2}$ insufflation $\left(\mathrm{CO}_{2}\right.$ pressure $\left.=8-10 \mathrm{mmHg}\right)$ was used to create an artificial pneumothorax inducing lung collapse on the operative field side.

After anesthesia induction, the radial artery and right internal jugular vein were punctured and catheterized. 
Table 1 Clinical characteristics and outcomes of the two groups

\begin{tabular}{lccc}
\hline & Group A & Group B & P value \\
\hline Number & 33 & 35 & - \\
Male/female & $18 / 15$ & $19 / 16$ & - \\
Age (month) & $6.9 \pm 2.3$ & $6.4 \pm 2.7$ & 0.79 \\
Weight (kg) & $7.0 \pm 1.4$ & $6.8 \pm 1.5$ & 0.59 \\
OLV time (min) & $51.5 \pm 8.2$ & $52.3 \pm 8.4$ & 0.68 \\
Length of drainage (day) & $2.5 \pm 0.6$ & $2.7 \pm 0.6$ & 0.43 \\
Length of hospital stay (day) & $5.4 \pm 0.8$ & $5.7 \pm 0.7$ & 0.49 \\
Surgical procedure (case) & & & \\
Pulmonary lobectomy & 14 & 14 & 0.90 \\
Pulmonary segmentectomy & 15 & 17 & \\
Partial pulmonary resection & 4 & 4 & \\
\hline
\end{tabular}

OLV: one-lung ventilation

The invasive mean arterial pressure (MAP) was monitored, and blood samples were collected for blood gas analysis during the operation. Arterial oxygen saturation was maintained between $92 \%$ and $96 \%$. Remifentanil at $0.1-0.5 \mu \mathrm{g} / \mathrm{kg} / \mathrm{min}$ and $1-3 \%$ sevoflurane were used to maintain anesthesia during the operation. The doses of remifentanil and sevoflurane were adjusted according to the monitoring values of anesthesia depth and blood pressure changes, HR, and end-expiratory carbon dioxide partial pressure $\left(\mathrm{PETCO}_{2}\right)$. If necessary, rocuronium $0.1 \mathrm{mg} / \mathrm{kg}$ was added. Recruitment maneuvers were performed in all infants at the end of OLV before restarting two-lung ventilation (TLV). In this study, a lung recruitment maneuver was performed three times, with airway pressure sustained at $30 \mathrm{~cm} \mathrm{H}_{2} \mathrm{O}$ for $15-20 \mathrm{~s}^{10)}$ Notably, during the operation, norepinephrine at $0.01-0.05 \mu \mathrm{g} / \mathrm{kg} /$ min was injected if the blood pressure was lower than $20 \%$ of the baseline. If the oxygen saturation was lower than $90 \%$, OLV was suspended, double-lung ventilation was resumed, and the bronchial blocker position was checked. OLV was performed after oxygen saturation was restored to $>96 \%$.

Data were collected from the computer record system, which included (1) general data such as age, sex, weight, time of OLV, length of drainage, and length of hospital stay; (2) the MAP of infants before OLV (T1), $10 \mathrm{~min}$ after OLV (T2), $30 \mathrm{~min}$ after OLV (T3), and $10 \mathrm{~min}$ after the end of OLV (T4); (3) the degree of lung collapse evaluated by the operating surgeon using a verbal rating scale from 0 (no lung deflation) to 10 (complete collapse) at the time of T2 and T3; ${ }^{11)}$ (4) incidence of intraoperative hypoxemia and hypotension during the operation (intraoperative hypoxemia was defined as $\mathrm{SpO}_{2}<90 \%$; hypotension was defined as blood pressure lower than $20 \%$ of the baseline); and (5) incidence of postoperative complications including pneumothorax, atelectasis, and chylothorax. An arterial blood sample was taken for blood gas analysis at T1, T2, T3, and T4 by the anesthetist during the operation. The $\mathrm{PaCO}_{2}$ value, oxygenation index $\left(\mathrm{PaO}_{2} / \mathrm{FiO}_{2}\right)$, and alveolar-arterial oxygen partial pressure difference $\left(\mathrm{PA}-\mathrm{aO}_{2}\right)$ data were also collected.

\section{Statistical analysis}

Statistical analysis was performed using SPSS software (25.0 Version, IBM Corp., Armonk, NY, USA). Data with a normal distribution were presented as the mean $\pm \mathrm{SD}$, and differences were evaluated using the t-test. Nonparametric data were presented as medians, and differences were evaluated using Wilcoxon rank sum. Categorical variables were shown as frequencies (percentages), and differences were evaluated using the $\chi 2$ test. A comparison of pulmonary gas exchange parameters pre-OLV, during OLV, and post-OLV was performed using repeated-measures analysis of variance. A P value of less than 0.05 was defined as statistically significant.

\section{Results}

The clinical information and outcomes of the two groups are shown in Table 1. There were no significant differences between the two groups in terms of clinical parameters, including age, sex, weight, time of OLV, length of drainage, and length of hospital stay $(\mathrm{P}>0.05)$. There were no significant differences between the two groups in length of drainage and hospital stay $(\mathrm{P}>0.05)$. In group A, there were 14 cases of lobectomy, 15 cases 
Wang J, et al.

Table 2 The comparison of perioperative hemodynamics and the degree of lung collapse score of the two groups

\begin{tabular}{lcccc}
\hline & Group A & Group B & P value & Z value \\
\hline T1 & & & & \\
MAP (mmHg) & $58.7 \pm 7.0$ & $56.7 \pm 8.1$ & 0.27 & - \\
HR (bpm) & $122.1 \pm 8.4$ & $119.7 \pm 11.3$ & 0.30 & - \\
T2 & & & - \\
MAP (mmHg) & $57.12 \pm 7.6$ & $42.8 \pm 4.9^{\mathrm{a}}$ & $<0.001$ & - \\
HR (bpm) & $118.6 \pm 10.2$ & $120.8 \pm 10$ & 0.37 & - \\
The degree of lung & $9.0(8.5,9.0)$ & $8.0(8.0,9.0)^{\mathrm{a}}$ & $<0.001$ & -3.489 \\
collapse score & & & & \\
T3 & & & \\
MAP (mmHg) & $52.6 \pm 7.6$ & $41.9 \pm 7.3^{\mathrm{a}}$ & $<0.001$ & - \\
HR (bpm) & $124.5 \pm 7.3$ & $125.2 \pm 10.7$ & 0.75 & - \\
The degree of lung & $10.0(9.0,10.0)$ & $9.0(9.0,9.0)^{\mathrm{a}}$ & $<0.001$ & -4.195 \\
collapse score & & & & \\
T4 & & & & \\
MAP (mmHg) & $57.9 \pm 4.0$ & $59.0 \pm 3.4$ & 0.17 & - \\
HR (bpm) & $119.3 \pm 9.8$ & $120.7 \pm 9.5$ & 0.54 & - \\
\hline
\end{tabular}

HR: heart rate; MAP: the mean arterial pressure. ${ }^{\text {a }}<0.001$ (indicate compared with group A).

of pulmonary segmentectomy, and 4 cases of partial pulmonary resection. In group B, there were 14 cases of lobectomy, 17 cases of pulmonary segmentectomy, and 4 cases of partial pulmonary resection. These results indicate that the two sets of data were comparable and homogeneous.

The comparison of the degree of lung collapse scores between the two groups is shown in Table 2. The degree of lung collapse score in group A was significantly higher than that in group B at T2 and T3 $(\mathrm{P}<0.001$, $\mathrm{z}=-3.489$ and $\mathrm{P}<0.001, \mathrm{z}=-4.195)$. A comparison of hemodynamic parameters between the two groups is shown in Table 2. There was no significant difference in MAP between the two groups at T1 and T4, but the MAP in group $\mathrm{B}$ was significantly lower than that in group A at T2 and T3 $(\mathrm{P}<0.001)$. There was no significant difference in HR between the two groups at any time point ( $\mathrm{P}>0.05)$. A comparison of the $\mathrm{PaCO}_{2}$ between the two groups is shown in Fig. 1. There were no significant differences in $\mathrm{PaCO}_{2}$ between the two groups at T1, T2, or T4. At T3, the $\mathrm{PaCO}_{2}$ in group B was significantly higher than that in group $\mathrm{A}(\mathrm{P}<0.001)$.

The comparison of $\mathrm{PaO}_{2} / \mathrm{FiO}_{2}$ and $\mathrm{PA}-\mathrm{aO}_{2}$ between the two groups is shown in Fig. 2. There were no significant differences in $\mathrm{PaO}_{2} / \mathrm{FiO}_{2}$ and $\mathrm{PA}-\mathrm{aO}_{2}$ between the two groups at any time point. However, there were significant differences when comparing these parameters at different time points in each group. In group A, compared with $\mathrm{T} 1$, the $\mathrm{PA}-\mathrm{aO}_{2}$ gradient at $\mathrm{T} 2$ and $\mathrm{T} 3$ significantly increased by 21.03 (95\% CI: 18.61-23.45) and 22.67 (95\% CI: 19.95-24.35), respectively $(\mathrm{P}<0.001)$; the $\mathrm{PaO}_{2} / \mathrm{FiO}_{2}$ ratio at $\mathrm{T} 2$ and $\mathrm{T} 3$ significantly decreased by 175.33 (95\% CI: 164.21-186.46) and 190.61 (95\% CI: 181.02-200.19), respectively ( $<<0.001)$. Compared with $\mathrm{T} 4$, the $\mathrm{PA}-\mathrm{aO}_{2}$ gradient at $\mathrm{T} 2$ and $\mathrm{T} 3$ significantly increased by 22.15 (95\% CI: 19.95-25.38) and 23.79 (95\% CI: 21.78-25.80), respectively ( $\mathrm{P}<0.001)$, whereas the $\mathrm{PaO}_{2} / \mathrm{FiO}_{2}$ ratio at $\mathrm{T} 2$ and $\mathrm{T} 3$ significantly decreased by 131.78 (95\% CI: $125.90-137.67)$ and 147.06 (95\% CI: 143.47-150.65), respectively ( $\mathrm{P}<0.001)$. In group B, compared with $\mathrm{T} 1$, the $\mathrm{PA}-\mathrm{aO}_{2}$ gradient at $\mathrm{T} 2$ and $\mathrm{T} 3$ significantly increased by 23.43 (95\% CI: 21.28-25.57) and 26.91 (95\% CI: 24.9-28.9), respectively ( $<<0.001)$. The $\mathrm{PaO}_{2} / \mathrm{FiO}_{2}$ ratio at $\mathrm{T} 2$ and $\mathrm{T} 3$ significantly decreased by 161.46 (95\% CI: $152.73-170.19)$ and 178.37 (95\% CI: 168.99-187.75), respectively $(\mathrm{P}<0.001)$. Compared with $\mathrm{T} 4$, the $\mathrm{PA}-\mathrm{aO}_{2}$ gradient at $\mathrm{T} 2$ and $\mathrm{T} 3$ significantly increased by 22.63 (95\% CI: 20.50-24.77) and 26.11 (95\% CI: 24.12-28.11), respectively $(\mathrm{P}<0.001)$. The $\mathrm{PaO} 2 / \mathrm{FiO} 2$ ratio at $\mathrm{T} 2$ and $\mathrm{T} 3$ significantly decreased by 159.40 (95\% CI: 154.89-163.93) and 176.31 (95\% CI: 172.69-179.94), respectively ( $\mathrm{P}<0.001)$.

The incidence of intraoperative and postoperative complications between the two groups is shown in Table 3. The hypotension incidence in group B was significantly higher than that in group $\mathrm{A}(\mathrm{P}<0.001)$. Hypoxemia occurred in both groups, but the incidence was not significantly different between the two groups $(\mathrm{P}=0.80)$. 


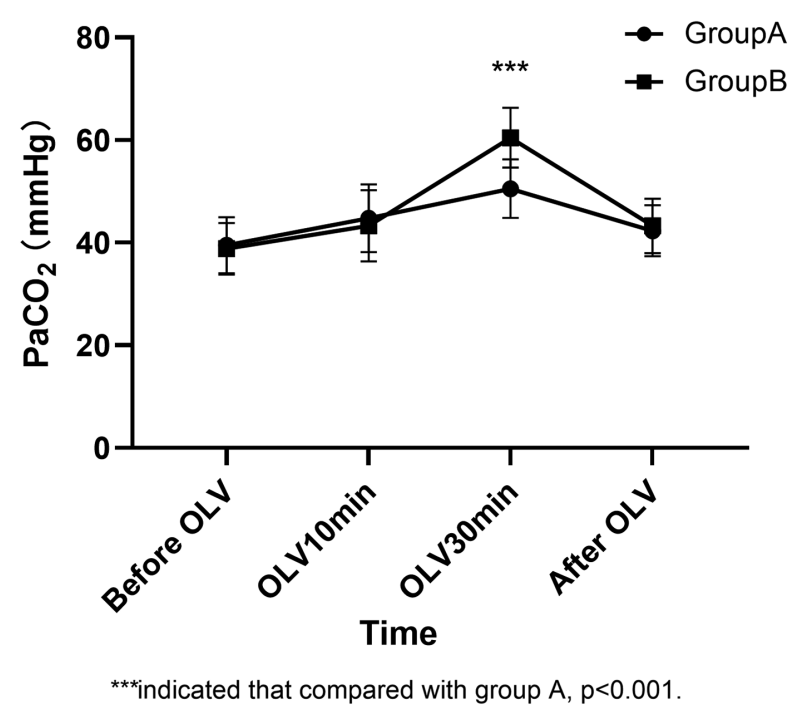

Fig. 1 The comparison of the $\mathrm{PaCO}_{2}$ between the two groups. $\mathrm{OLV}$ : one-lung ventilation; $\mathrm{PaCO}_{2}$ : partial pressure of carbon dioxide

There was no significant difference in the incidence of postoperative complications between the two groups.

\section{Discussion}

Compared to conventional surgery, VATS is a minimally invasive method in thoracic surgery and has many advantages, such as a small incision, less postoperative pain, fewer postoperative complications, and a shorter hospital stay, promoting the postoperative recovery of patients. Therefore, VATS has been widely accepted by parents for their children. ${ }^{12)}$ During the operation, it is necessary to collapse the lung on the operating side to expose the surgical field of vision, which is needed and beneficial for the surgeon to perform the operation. Collapse of the unilateral lung during the operation can be implemented using a bronchial blocker, a doublelumen tube, and $\mathrm{CO}_{2}$ artificial pneumothorax. However, the smallest model of the double-lumen tube is only suitable for children over 8 years old. ${ }^{13)}$ In VATS, intrathoracic positive pressure injection of $\mathrm{CO}_{2}$ can provide adequate lung collapse and promote visual surgical field exposure. However, this approach may lead to the accumulation of $\mathrm{CO}_{2} \cdot{ }^{14,15)}$ The use of a bronchial blocker is suitable for infants and young children. In general, the bronchial blocker is placed in the endotracheal tube and located via fiberoptic bronchoscope guidance. When infants undergo endotracheal intubation, an endotracheal tube of ID $3.5 \#$ or $4.0 \#$ is generally selected. Due to the limitation of the endotracheal tube's inner diameter, the fiberoptic bronchoscope and bronchial blocker cannot enter the endotracheal tube simultaneously. Therefore, we typically place the bronchial blocker outside the endotracheal tube to implement lung collapse for infants under 1 year old.

In this study, a single-lumen endobronchial tube was used for endotracheal intubation in both groups. Lung collapse was induced during surgery via the compression of $\mathrm{CO}_{2}$ flow or the bronchial blocker to provide surgical vision and operating space. At T2 and T3, the degree of lung collapse of group A was greater than that of group B, indicating that the visual surgical field exposed by the bronchial blocker was better than that by $\mathrm{CO}_{2}$ artificial pneumothorax. Zheng et al. and Yan et al. reported that the use of a bronchial blocker for lung collapse provides an adequate surgical field of vision. ${ }^{9,16)}$

The MAP of group B was significantly lower than that of group A at T2 and T3. The incidence of intraoperative hypotension in group B was significantly higher than that in group A. Mohtar et al. also reported no significant change in blood pressure before, during, or after bronchial blocker use. ${ }^{17)}$ We considered that the pressure of $\mathrm{CO}_{2}$ during $\mathrm{CO}_{2}$ artificial pneumothorax could compress the heart and large blood vessels, resulting in reduced cardiac blood volume, transient or persistent hypotension, and even the need to use vasoactive drugs. ${ }^{18)}$

At T3, the $\mathrm{PaCO}_{2}$ of group B was significantly higher than that of group A. We believe that this finding might have been due to the accumulation of $\mathrm{CO}_{2}$ in the chest cavity after 30 minutes of artificial pneumothorax in the infants of group $\mathrm{B}$, which resulted in acidosis and elevated $\mathrm{PaCO}_{2}$ levels in the arterial blood. This observation was consistent with the research of Lin et al. ${ }^{14)}$ However, there was no significant difference in $\mathrm{PaCO}_{2}$ between the two groups at T4. The reason might be due to the following operations performed at the end of the surgery. First, OLV was stopped immediately, and TLV was resumed. Second, the $\mathrm{CO}_{2}$ was evacuated from the infants' thoracic cavity by the surgeon. Third, the infant was switched from the lateral to the supine position, and the lung recruitment maneuver was carried out. It has been reported that lung recruitment maneuvers improve oxygenation during OLV. ${ }^{19}$ ) Therefore, the $\mathrm{PaO}_{2}$ and $\mathrm{PaCO}_{2}$ levels were significantly improved in blood gas analysis 10 minutes after OLV. 
Wang J, et al.

A1

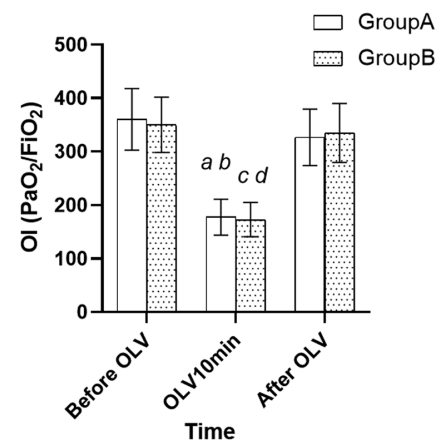

$a$ indicated that compared with the time of T1 (before OLV) in group $\mathrm{A}, p<0.001$ $b$ indicated that compared with the time of T4 (after OLV) in group A, $p<0.001$

$c$ indicated that compared with the time of T1 (before OLV) in group $B, p<0.001$; $d$ indicated that compared with the time of T4 (after OLV) in group $B, p<0.001$.

B1

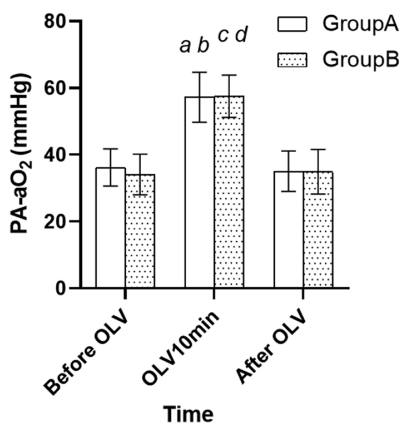

$a$ indicated that compared with the time of T1 (before OLV) in group $A, p<0.001$; $b$ indicated that compared with the time of T4 (after OLV) in group $A, p<0.001$; $c$ indicated that compared with the time of T1 (before OLV) in group $B, p<0.001$; $d$ indicated that compared with the time of T4 (after OLV) in group B, $p<0.001$.
A2

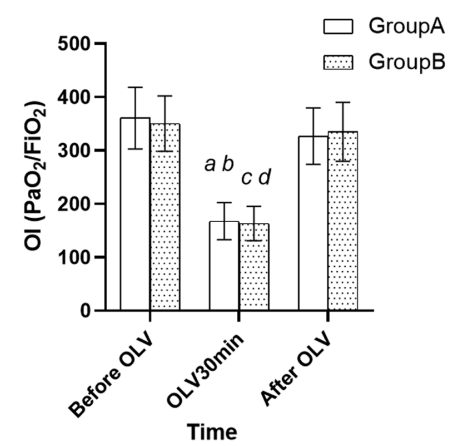

$a$ indicated that compared with the time of T1 (before OLV) in group $A, p<0.001$; $b$ indicated that compared with the time of T4 (after OLV) in group $A, p<0.001$; $c$ indicated that compared with the time of T1 (before OLV) in group $B, p<0.001$; $d$ indicated that compared with the time of T4 (after OLV) in group $\mathrm{B}, p<0.001$.

\section{B2}

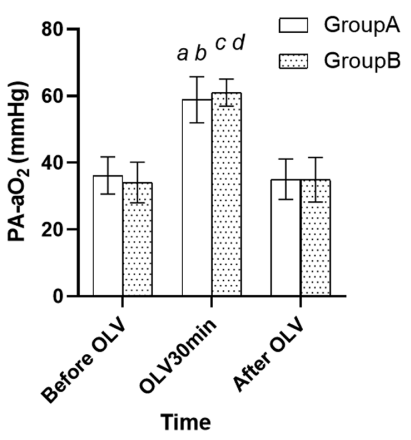

$a$ indicated that compared with the time of T1 (before OLV) in group $A, p<0.001$ $b$ indicated that compared with the time of T4 (after OLV) in group A, $p<0.001$; $c$ indicated that compared with the time of T1 (before OLV) in group $B, p<0.001$; $d$ indicated that compared with the time of T4 (after OLV) in group $\mathrm{B}, p<0.001$.

Fig. 2 The comparison of $\mathrm{PaO}_{2} / \mathrm{FiO}_{2}$ and $\mathrm{PA}-\mathrm{aO}_{2}$ between the two groups. A1 showed the comparison of $\mathrm{PaO}_{2} / \mathrm{FiO}{ }_{2}$ at the time of T1, $\mathrm{T} 2$ and $\mathrm{T} 4$ between the two groups. A2 showed the comparison of $\mathrm{PaO}_{2} / \mathrm{FiO}_{2}$ at the time of $\mathrm{T} 1$, T3, and T4 between the two groups. $\mathrm{B} 1$ showed the comparison of $\mathrm{PA}-\mathrm{aO}_{2}$ at the time of $\mathrm{T} 1, \mathrm{~T} 2$, and $\mathrm{T} 4$ between the two groups. $\mathrm{B} 2$ showed the comparison of PA- $\mathrm{aO}_{2}$ at the time of $\mathrm{T} 1, \mathrm{~T} 3$, and $\mathrm{T} 4$ between the two groups. $\mathrm{FiO}_{2}$ : fraction of inspired oxygen; OLV: one-lung ventilation; $\mathrm{PA}-\mathrm{aO}_{2}$ : alveolar-arterial oxygen partial pressure difference; $\mathrm{PaO}_{2}$ : partial pressure of oxygen; $\mathrm{PaO}_{2} / \mathrm{FiO}_{2}$ : Oxygenation Index; T1: before OLV; T2: 10 min after OLV; T3: 30 min after OLV; T4: 10 min after the end of OLV

Table 3 Comparison of intraoperative and postoperative complications of the two groups

\begin{tabular}{lccc}
\hline Parameter & Group A & Group B & P value \\
\hline Number of patient & \multicolumn{1}{c}{33} & 35 & - \\
Intraoperative hypotension: case (\%) & $5(15.2)$ & $28(80)^{\mathrm{a}}$ & $<0.001$ \\
Intraoperative hypoxemia:case (\%) & $15(45.5)$ & $17(48.6)$ & 0.88 \\
Postoperative complications & & & \\
Pneumothorax:case (\%) & $2(6.0)$ & $3(8.6)$ & 0.71 \\
Atelectasis:case (\%) & $1(3.0)$ & $2(5.7)$ & 0.61 \\
Chylothorax:case (\%) & $1(3.0)$ & $0(0)$ & 0.31 \\
\hline
\end{tabular}

${ }^{\text {aP }}<0.001$ (indicate compared with group A).

During OLV in infants in the lateral decubitus position, the risk of hypoxemia is higher due to increased V/Q mismatch, compression of the healthy-side lung, and collapse of the surgical-side lung with higher oxygen consumption. ${ }^{20,21)}$ In this retrospective study, we observed no significant differences in the $\mathrm{PaO}_{2} / \mathrm{FiO}_{2}$ ratio or $\mathrm{PA}-\mathrm{aO}_{2}$ between the two groups at any time point. However, at $\mathrm{T} 2$ and $\mathrm{T} 3$, the $\mathrm{PaO}_{2} / \mathrm{FiO}_{2}$ ratio decreased, and the $\mathrm{PA}-\mathrm{aO}_{2}$ increased in both groups, indicating a change in pulmonary function and a higher risk of hypoxemia in OLV. At T4, when OLV was stopped for 10 minutes, the $\mathrm{PaO}_{2} / \mathrm{FiO}_{2}$ ratio and $\mathrm{PA}-\mathrm{aO}_{2}$ returned 
to baseline levels. Hale et al. reported the same situation in infants undergoing OLV. ${ }^{22}$ There was no significant difference in the incidence of hypoxemia between the two groups in this study. The state of hypoxemia can be quickly improved by suspending the operation and performing TLV.

This research had some limitations. The sample size included in this study was relatively small. In addition, our data collection might have been biased. Relatively, few indicators of pulmonary function were adopted in the study, a subjective rating scale was used to evaluate the degree of pulmonary collapse, and the data could have become biased in the recording process, which, in turn, could affect the accuracy of the results. In addition, this study was retrospective rather than a prospective case-control study, which limited its statistical power, but we still believe that the results have clinical significance. Future research should consider variations in factors and examine a larger sample to confirm our conclusions.

\section{Conclusion}

This study showed that OLV with extraluminal placement of a bronchial blocker is a safe choice for infants undergoing VATS. In our study, the gas exchange changed during OLV but returned to baseline following resumption of TLV. Compared with $\mathrm{CO}_{2}$ artificial pneumothorax, OLV with extraluminal placement of a bronchial blocker appears to provide a higher degree of surgeon-rated lung collapse, fewer episodes of significant hypotension, and lower $\mathrm{PaCO}_{2}$ accumulation for infants undergoing VATS.

\section{Acknowledgments}

We appreciate all doctors and nurses in our center for fruitful advice and discussions. We hope humans eventually defeat COVID-19.

\section{Disclosure Statement}

All authors declared that they had no competing interests.

\section{References}

1) Zhang R, Liu $S$, Sun $H$, et al. The application of single-lumen endotracheal tube anaesthesia with artificial pneumothorax in thoracolaparoscopic oesophagectomy. Interact Cardiovasc Thorac Surg 2014; 19: 308-10.

2) Cai L, Li Y, Sun L, et al. Better perioperative outcomes in thoracoscopic-esophagectomy with two-lung ventilation in semi-prone position. J Thorac Dis 2017; 9: $117-22$.

3) Lin M, Shen $Y$, Wang $H$, et al. A comparison between two lung ventilation with $\mathrm{CO} 2$ artificial pneumothorax and one lung ventilation during thoracic phase of minimally invasive esophagectomy. J Thorac Dis 2018; 10: 1912-8.

4) Baek SY, Kim JH, Kim G, et al. Successful one-lung ventilation by blocking the right intermediate bronchus in a 7-year-old child: a case report. J Int Med Res 2019; 47: 2740-5.

5) Hoşten T, Aksu C, Kuş A, et al. Comparison of univent tube and EZ blocker in one lung ventilation; airway pressures and gas exchange. J Clin Monit Comput 2018; 32: 327-33.

6) Stephenson LL, Seefelder C. Routine extraluminal use of the 5F Arndt endobronchial blocker for onelung ventilation in children up to 24 months of age. J Cardiothorac Vasc Anesth 2011; 25: 683-6.

7) Templeton TW, Downard MG, Simpson CR, et al. Bending the rules: a novel approach to placement and retrospective experience with the 5 French Arndt endobronchial blocker in children $<2$ years. Paediatr Anaesth 2016; 26: 512-20.

8) Chen $\mathrm{H}$, Zhang $\mathrm{K}, \mathrm{Gu} \mathrm{H}$, et al. A new technique to facilitate lung lavage for pulmonary alveolar proteinosis in a 3-month-old infant: Bronchial-blocker-out-ofendotracheal-tube technique. J Clin Anesth 2020; 59: 82-3.

9) Yan J, Rufang Z, Rong W, et al. Extraluminal placement of the bronchial blocker in infants undergoing thoracoscopic surgery: A randomized controlled study. J Cardiothorac Vasc Anesth 2020; 34: 2435-9.

10) Duff JP, Rosychuk RJ, Joffe AR. The safety and efficacy of sustained inflations as a lung recruitment maneuver in pediatric intensive care unit patients. Intensive Care Med 2007; 33: 1778-86.

11) Yoshimura $T$, Ueda $K$, Kakinuma A, et al. Bronchial blocker lung collapse technique: nitrous oxide for facilitating lung collapse during one-lung ventilation with a bronchial blocker. Anesth Analg 2014; 118: 666-70.

12) Fabila TS, Menghraj SJ. One lung ventilation strategies for infants and children undergoing video assisted thoracoscopic surgery. Indian J Anaesth 2013; 57: 339-44.

13) Bansal T, Kiran S, Kamal K, et al. Anesthetic management for lobectomy of a 2-month-old infant with bronchogenic cyst: case report along with review of literature. Saudi J Anaesth 2017; 11: 340-2.

14) Lin $M$, Shen $Y$, Wang H, et al. A comparison between two lung ventilation with $\mathrm{CO} 2$ artificial pneumothorax and one lung ventilation during thoracic phase 
Wang J, et al.

of minimally invasive esophagectomy. $\mathrm{J}$ Thorac Dis 2018; 10: 1912-8.

15) Nomura $S$, Tsujimoto $H$, Ishibashi $Y$, et al. Efficacy of artificial pneumothorax under two-lung ventilation in video-assisted thoracoscopic surgery for esophageal cancer. Surg Endosc 2020; 34: 5501-7.

16) Zheng M, Niu Z, Chen P, et al. Effects of bronchial blockers on one-lung ventilation in general anesthesia: A randomized controlled trail. Medicine (Baltimore) 2019; 98: e17387.

17) Mohtar S, Hui TWC, Irwin MG. Anesthetic management of thoracoscopic resection of lung lesions in small children. Paediatr Anaesth 2018; 28: 1035-42.

18) Saikawa D, Okushiba S, Kawata M, et al. Efficacy and safety of artificial pneumothorax under twolung ventilation in thoracoscopic esophagectomy for esophageal cancer in the prone position. Gen Thorac Cardiovasc Surg 2014; 62: 163-70.

19) Peel JK, Funk DJ, Slinger P, et al. Positive endexpiratory pressure and recruitment maneuvers during one-lung ventilation: a systematic review and meta-analysis. J Thorac Cardiovasc Surg 2020; 160: 1112-22.e3.

20) Hammer GB. Pediatric thoracic anesthesia. Anesth Analg 2001; 92: 1449-64.

21) Shaffer TH, Wolfson MR, Panitch HB. Airway structure, function and development in health and disease. Paediatr Anaesth 2004; 14: 3-14.

22) Hale JE, Meador MR, Mossad EB. Lung separation in children: Options and impact on gas exchange and lung compliance. Paediatr Anaesth 2019; 29: 915-9. 